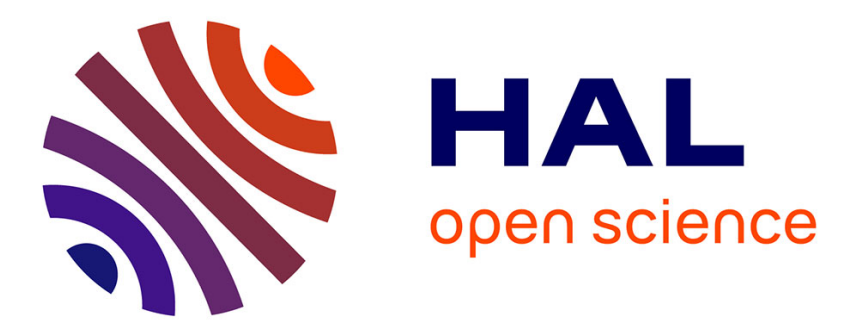

\title{
Satellite measurements as a constraint on estimates of vegetation carbon budget
}

Laurent Kergoat, Alberte Fischer, Sophie Moulin, Gérard Dedieu

\section{To cite this version:}

Laurent Kergoat, Alberte Fischer, Sophie Moulin, Gérard Dedieu. Satellite measurements as a constraint on estimates of vegetation carbon budget. Tellus B - Chemical and Physical Meteorology, 1995, 47B, pp.251-263. 10.1034/j.1600-0889.47.issue1.21.x . hal-02713822

\section{HAL Id: hal-02713822 \\ https://hal.inrae.fr/hal-02713822}

Submitted on 1 Jun 2020

HAL is a multi-disciplinary open access archive for the deposit and dissemination of scientific research documents, whether they are published or not. The documents may come from teaching and research institutions in France or abroad, or from public or private research centers.
L'archive ouverte pluridisciplinaire HAL, est destinée au dépôt et à la diffusion de documents scientifiques de niveau recherche, publiés ou non, émanant des établissements d'enseignement et de recherche français ou étrangers, des laboratoires publics ou privés. 


\title{
Satellite measurements as a constraint on estimates of vegetation carbon budget
}

\author{
By LAURENT KERGOAT*, ALBERTE FISCHER, SOPHIE MOULIN and GÉRARD DEDIEU, \\ LERTS (CNES/CNRS), 18 avenue E. Belin (bpi 2801), F-31055 Toulouse Cedex, France
}

(Manuscript received 2 December 1993; in final form 29 August 1994)

\begin{abstract}
A methodology for coupling prognostic models of vegetation and remote sensing measurements is presented. This approach, based on control theory, postulates that errors in model parameters or initial states can be corrected, by minimizing the differences between satellite observations and modelled reflectances. These reflectances are computed from model state variables, (carbon in the leaves) with a direct "scene" model. The differences between this approach and previous studies dealing with the coupling of satellite data and vegetation modelling are briefly discussed. A synthetic experiment with a generic vegetation model, designed for carbon cycle investigations, shows that processes such as allocation of carbon to the leaves and phenological behavior of a deciduous-forest canopy can be controlled, and that carbon exchanges estimation can then be improved. Furthermore, we show that assimilation of real satellite observations in a crop model leads to improved simulation of vegetation functioning, as ground-truth information confirms that a good retrieval of the sowing date, the control parameter, is achieved. Finally, we point out the interests and requisites for application to natural vegetation carbon fluxes estimations at the global scale.
\end{abstract}

\section{Introduction}

Atmospheric $\mathrm{CO}_{2}$ and $\delta^{13} \mathrm{C}$ measurements, which provide integrated information on biospheric, oceanic and anthropogenic carbon fluxes, exhibit strong spatial and temporal variability (seasonal fluctuations and trend). Seasonal modelling of vegetation functioning is therefore of great interest. Interannual variability, resulting from ENSO events or aerosol emission from Pinatubo (Sarmiento, 1993) also gives test-cases to estimate the accuracy of biosphere models and attempt to reduce current uncertainties. Moreover, if we are to develop predictive capabilities, and assess future biospheric sources and sinks, we need to understand and model their evolution. As far as the continental biosphere is concerned, net primary productivity (NPP) and soil respiration show dif-

\footnotetext{
* Corresponding author.
}

ferent responses to climate forcing and therefore need to be modelled separately. Recent studies based on ${ }^{18} \mathrm{O}$ fractionation (Farquhar et al., 1993) encourage mechanistic modelling of photosynthesis, transpiration and other processes, by providing additional information on the biospheric contribution to the global carbon cycle. This suggests that prognostic process vegetation models, especially if seasonal and inter-annual variability can be assessed, are among the most promising tools to address the response of the global system to anthropogenic perturbations (Agren et al., 1991; Mellilo et al., 1993). Furthermore, in addition to atmospheric $\mathrm{CO}_{2}$ monitoring, global satellite archive now provides radiometric measurements with remarkable spatial coverage and temporal repetitivity. These considerations: (a) validation opportunities based on seasonal and inter-annual variability over the last decade; (b) the interest in prognostic vegetation model development; (c) emergence of global remotely 
sensed data, are basic reasons for studying the coupling of vegetation model and satellite measurements. In this paper, we propose a methodology to constrain a vegetation model with remote sensing data (Section 2). In Section 3, we present a synthetic experiment of this new approach with a generic vegetation model, and then (Section 4) show a validation at the field level, using a crop model over a site where we have independent ground-based knowledge. Finally, we discuss the possible contribution of satellite data assimilation to global carbon cycle studies and spatialization of biosphere models.

\section{Context}

Coupling vegetation model (at regional-toglobal scale) and remote sensing data has led to several studies which differ in the complexity of the vegetation modelling and in the kind of information (qualitative or quantitative) derived from satellite data. Fung et al. (1987) estimated a seasonal distribution of annual NPP, using empirical relationships between AVHRR/NDVI (normalized difference vegetation index from the advance very high resolution radiometer) time series and photosynthesis. They showed that phasing of the biospheric $\mathrm{CO}_{2}$ fluxes can be assessed, and is of special interest when comparing with atmospheric $\mathrm{CO}_{2}$ seasonal oscillations. Several authors also used Monteith model (Monteith 1972) and derived absorbed photosynthetically active radiation (APAR) from NDVI and incident solar radiation. APAR is then transformed into dry matter (NPP) through a biological efficiency coefficient. Examples of these studies are Heimann and Keeling (1989) and Ruimy et al. (1994). A major advantage of these diagnostic studies is that the response of the vegetation to environment conditions is, to some extent, included in the satellite signal. Precise evaluation of errors in both model and satellite archive is expected to give interesting results on interannual variability. More mechanistic vegetation models have also been coupled with remote sensing data. These studies are based on two different approaches.

(a) Forcing strategies: biophysical variables are derived from the satellite signal, through inversion or empirical relationship, and then used as input in a process vegetation model. Regional scale inversion of LAI (Leaf Area Index) over coniferous forests and inclusion in Forest-BGC is presented by Running et al. (1989). Lüdecke et al. (1991) also performed LAI inversion from AVHRR data over a small area dominated by deciduous forest, and used it to drive the Frankfurt biosphere model (Janececk et al., 1989). However, these inversion schemes exhibit a strong sensitivity to signal noise, and high LAI values (e.g., $\mathrm{LAI}>4$ ) are not accurately obtained, especially because reflectances in the solar spectrum become insensitive to $\mathrm{LAI}$ at these high values.

(b) Comparison/validation: these approaches consist of deriving surface radiative properties from a vegetation model and comparing them with remote sensing data. Woodward and Smith (1993) compared NDVI estimates computed from an ecophysiological prediction of LAI and AVHRR measurements over several African reserves, in order to assess the validity of their model assumptions. Another interesting example of validation is discussed by Nemani and Running (1989), who compared NDVI derived from AVHRR data over coniferous forests and outputs of an ecosystem model, to test an ecological concept of equilibrium between LAI and water availability. These studies highlight the potential for indirect use of remote sensing data.

In this paper, we use the comparison between a prognostic model and data to improve the model prediction. This methodology, hereafter referred as control or re-calibration, is related to variational assimilation developed in atmospheric research and oceanography (Le Dimet and Talagrand, 1986). The purpose is to find the model trajectory which leads to the best agreement with a set of observations distributed in time. If $X$ represents the model variables, the model can be written as $F(X, u)=0$, where $u$, the control variables, are inputs leading to a unique model evolution. The discrepancy between the model and the data can be measured by

$J(u)=\int_{0}^{T}\left\|C \cdot X-O_{\mathrm{d}}\right\|^{2} \mathrm{~d} t$,

where $O_{\mathrm{d}}$ is the set of observations belonging to the time interval $[0, T]$, and $C$ a mapping from the state space to the observation space. The problem is then to minimize $J(u)$ under the constraint 
$F(X, u)=0$. In our case, $C$ is a "scene" model which computes reflectances from the vegetation state variables. For meteorological studies, the control is usually the initial state of some $3 \mathrm{D}$ fields, because this causes the main errors in the prediction, when compared, for instance, to physical parameterizations schemes. This is not the case for ecological studies, where general consensus on model laws usually does not exist. This means that control "variables" can be chosen among model parameters as well as among initial conditions.

\section{Synthetic experiment with a biosphere model}

In this section, we present the potential of the control strategy based on satellite data in the solar spectrum, when applied to a vegetation model, with special focus on carbon fluxes.

\subsection{Model description}

The linkage of a vegetation model and global remote sensing data requires that the model is able to predict radiative properties of the surface at the same time and space scales as available satellite measurements. Evolution of the canopy structure with time has to be explicitly simulated, especially when seasonal changes occur. These changes, which are driven by both environmental and internal factors, will be referred as phenological events (for instance, leaf shooting, senescence, abscission, dormancy). In what follows, we present the general frame of the generic vegetation model that we have developed, and provide a more extensive description in Appendix. The system is described by 4 carbon compartments (which average the leaves, stems, roots and storage over a given area) and a soil water bucket model. The fluxes between these reservoirs depend on daily climate input (daily minimum and maximum temperature, precipitation, irradiance, net radiation, vapor pressure deficit) and parameters associated with phenological stage and vegetation type (e.g., annual/perennial evergreen/deciduous...). Carbon and water fluxes are coupled through the stomatal resistance. The fluxes sub-models mainly follow Running and Coughlan (1988), and Bonan (1991a, b). Nutrient cycling has not been considered. For simulation over a 10 -year period, nutrient limitation may be implicitly prescribed in the parameter set. As far as carbon is concerned, the model consists in a set of differential equations:

$$
\begin{aligned}
& \frac{\mathrm{d} G}{\mathrm{~d} t}=a_{1}(t)[f(G, t)+h(t)]-g(G, t), \\
& \frac{\mathrm{d} M_{i}}{\mathrm{~d} t}=a_{i}(t)[f(G, t)+h(t)]-g\left(M_{i}, t\right),
\end{aligned}
$$

where $G$ is the carbon content of leaves, $M_{i}$ the carbon content of stems, roots and storage $(i=2$ to 4$), f(G)$ is the photosynthesis rate, $h(t)$ is the rate of carbon translocation from storage, and $g\left(M_{i}\right)$ is the sum of carbon losses due to autotrophic respiration and mortality.

Our assumption is that the $a_{i}(t)$ functions are driven by the phenology and link the carbon fluxes with the canopy development. Many crop models are built on the same hypothesis, e.g., AFRCWHEAT2 (Porter, 1993) used in Section 4. These equations are solved with a one-day time step. The main outputs are the atmosphere/vegetation $\mathrm{CO}_{2}$ fluxes, litterfall, and carbon compartments. A complete description or validation of the model is beyond the scope of this paper, but we assume here that system dynamics are reasonably well simulated. Once the relevant processes have been identified and modelled, the model requires parameter sets which, ideally, are measured and accurate enough to allow satisfying simulation of vegetation functioning. This is a critical issue, especially when spatialization (extension to the whole biome geographic range) is considered. For instance, Bonan (1993) pointed out the importance of vegetation type and LAI in estimating boreal forest carbon fluxes. At the global scale, modelling autotrophic respiration, carbon partitioning and phenology for example is expected to be improved, for process models are sensitive to these parameterizations. The methodology that we propose in this paper is to use satellite observations to correct the model course and hence to provide greater confidence in $\mathrm{CO}_{2}$ flux estimation than before.

\subsection{Data assimilation}

With the model, we simulate a deciduous forest ecosystem, as an example of canopy which shows a pronounced seasonality. Daily meteorological inputs have been collected at Boigneville (latitude $48^{\circ}$, France) for 1992 . At this site, the vegetation 
growing season is from April to October, with winter dormancy and possible limited summer water stress. The purpose here is to have a reasonable simulation of natural vegetation, but not to model a real forest site. At this step, assimilation in this vegetation model has not been investigated with satellite data. However, we carried out an academic exercise, a synthetic experiment, which is a classical approach to address inversion of remote sensing data. The main questions concern the feasibility and stability of assimilation scheme.

3.2.1. Choice of the control parameters. This subsection presents the three control parameters $\left(\Sigma_{1}, \Sigma_{2}\right.$ and $\left.\alpha\right)$ chosen for the synthetic study and details the processes that they parameterize. Suitable control parameters must clearly be important drivers of the surface radiative properties, must suffer from large uncertainties and, finally, must modulate substantially the carbon flux simulation. Phenology modelling and allocation of carbon to the leaves both fit these criteria.

Phenology. For "seasonal" ecosystems, canopy development is known to be a fundamental driver of gas exchange, when time scales of day to months are considered (Körner, 1993). For different vegetation types, internal control of development can be modelled as a response to environmental factors: for example, heat sum, photoperiod and chilling requirement for temperate ecosystems (Murray et al., 1989; Nisinsky and Saugier, 1988), and soil water availability for arid zones and savannahs. As our simulation aims to reproduce a deciduous temperate forest, the development has been parameterized as a function of cumulated daily (positive) mean temperature starting on the 1 st of January. Two phenological events have been modelled: (a) the start of the growing period: as soon as a threshold $\Sigma_{1}$ of cumulated temperatures is reached, carbon is translocated from the storage compartment (until it is empty) to allow leaf growth and photosynthesis. (b) the start of the senescence period: when a threshold $\Sigma_{2}$ is reached, abscission of leaves occurs at a constant rate.

Allocation of assimilates. Eq. (2.1) shows that the daily growth of the different compartments depends on allocation coefficients applied on photosynthesis and carbon translocation. Carbon partitioning is one of the major difficulties in process oriented vegetation modelling. Important feedbacks between fluxes and structure occur in annual herbaceous vegetation and also in perennial ecosystems and therefore must be addressed (particularly when behavior over several years is considered). For this forest simulation, we consider a simple seasonal allocation pattern, associated with the two phenological events previously defined, and assuming that the allocation coefficients can be interpolated between these events as a linear function of cumulated temperature. The number of control parameters being limited, because of the inverse modelling approach, we further assume that the allocation pattern mainly depends on a single coefficient $\alpha$ : at the beginning of the growing season, allocation to leaves, stems, roots, storage compartments is $\alpha$, $(1-\alpha) / 2,(1-\alpha) / 2,0$, respectively, and $[0,0,0,1]$, respectively, at the beginning of the senescence period. The third control parameter is thus $\alpha$.

Reference simulation. These three parameters $\left(\Sigma_{1}, \Sigma_{2}\right.$ and $\left.\alpha\right)$ have been chosen to give a reasonable LAI time profile (Table 1 and Fig. 1 ). Quasi-linear increase at the beginning of the growing season is due to carbon translocation from storage, which stops when the storage compartment is empty, resulting in a sudden change in slope. Quasi-linear decrease corresponds to the senescence phase. The net $\mathrm{CO}_{2}$ flux (photosynthesis minus autotrophic respiration) is shown in Fig. 2 (a) Gross Primary Productivity (GPP) is $1011 \mathrm{~g} \mathrm{C} \mathrm{m}^{-2}$ year ${ }^{-1}$ and NPP $625 \mathrm{~g} \mathrm{C} \mathrm{m}^{-2}$

Table 1. Reference, 1st guess parameters and retrieved values after assimilation of "clean observations"

\begin{tabular}{|c|c|c|c|c|c|}
\hline & $\Sigma_{1}(\mathrm{~d} . \mathrm{d})$ & $\Sigma_{2}(\mathrm{~d} . \mathrm{d})$ & $\alpha$ & $\begin{array}{c}\text { GPP } \\
\left(\mathrm{gC} \mathrm{m}^{-2} \mathrm{yr}^{-1}\right)\end{array}$ & $\begin{array}{c}\text { NPP } \\
\left(\mathrm{gC} \mathrm{m}^{-2} \mathrm{yr}^{-1}\right)\end{array}$ \\
\hline reference & 600 & 3200 & 0.480 & 1010 & 625 \\
\hline 1st guess & 1000 & 3700 & 0.45 & 740 & 392 \\
\hline retrieval & 602.9 & 3201.9 & 0.479 & 1011 & 625 \\
\hline
\end{tabular}




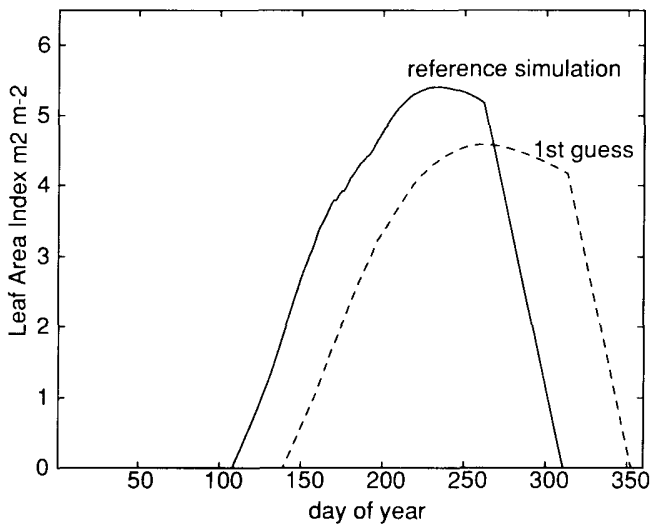

Fig. 1. Seasonal profile of leaf area index, obtained with the reference parameter set and the first guess, for which GPP is decreased by $26 \%$ and NPP by $37 \%$.

year ${ }^{-1}$, these values are within the range of published data for temperate deciduous forests (Lieth, 1975).

Reflectance model. The foliar surface, predicted by the vegetation model, along with prescribed optical properties and real view and solar angles
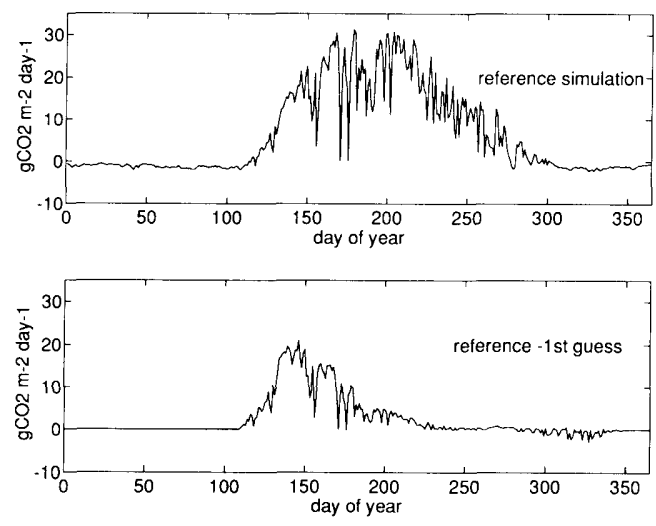

Fig. 2. (a) Daily net $\mathrm{CO}_{2}$ exchange between vegetation and atmosphere for the reference simulation. Positive values correspond to assimilation of $\mathrm{CO}_{2}$ by the vegetation, when photosynthesis is the dominant process, while negative values outside the growing season are due to stem maintenance respiration. (b) Difference in net $\mathrm{CO}_{2}$ between the reference and the first guess simulations. The reference canopy develops earlier and allows high photosynthesis thanks to spring warm temperature and high irradiance leading to high positive values. In contrast, after day 300 , although the "lst guess" canopy is still developed, photosynthetic rate is rather low and the difference of net $\mathrm{CO}_{2}$ fluxes take small negative values. are used to compute, with the SAIL model (scattering by arbitrarily inclined leaves, Verhoef, 1984), red and near-infrared reflectances, corresponding to the AVHRR spectral bands. This model takes soil and directional effects into account and has been validated against ground data. The main assumption here is that LAI is the strongest driver of the reflectance signal. Satellite data have to be filtered to avoid contamination by clouds and occurrences of thick atmosphere, and this filtering reduces the number of available data. Our "observations" have therefore been sampled to weekly data, to give a realistic frequency of measurements. Resulting reflectances are shown on Fig. 3. Canopy development leads to an increase in the near infra-red band, and a decrease in the visible band. The soil is assumed to be lambertian, while the directional properties of the vegetation result in high frequency variability, caused by the orbital cycle of the satellite.

\subsubsection{Synthetic experiment. Synthetic "obser-} vations" consist of reflectances computed from the outputs of the reference simulation of the model using the reference parameter set $\left(\Sigma_{1}, \Sigma_{2}\right.$, $\alpha$ and others parameters given in Appendix). The reference run is assumed to mimic the observations

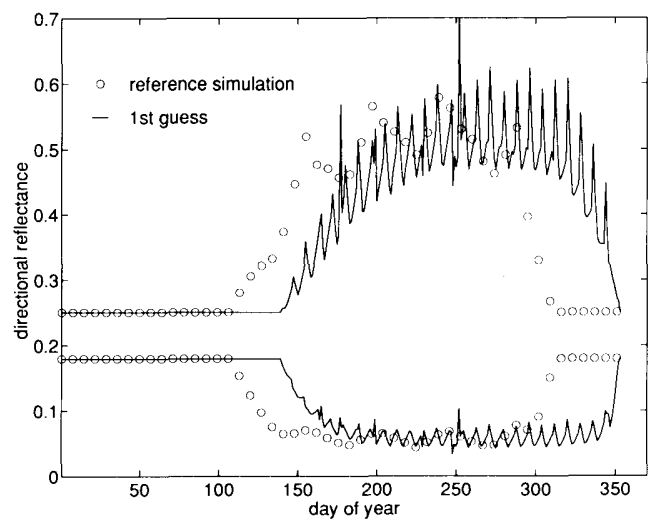

Fig. 3. Seasonal profile of reflectances. Open circles are the synthetic weekly "observations" computed with the LAI time profile from the reference simulation. The visible reflectance ranges from 0.18 (bare soil) to 0.044 at maximum canopy development. The near infrared ranges from 0.24 (bare soil) to 0.57 . The solid line represents daily reflectances obtained with the first guess parameters, the pikes resulting from AVHRR orbital cycle. 
that would be acquired over real vegetation. The basic assumption is that the model is perfect.

We then suppose that we do not know some of these parameters accurately: Indeed, when a vegetation model is applied to different sites under different environmental forcing, the parameters which are specified are extrapolated from local studies or based on theoretical assumptions and may be poorly known. These a priori values, which depart more or less from the reference values, are the 1st guess parameter set. The discrepancy between model and "observations" is then minimized, starting from the 1st guess parameters, and this leads to a retrieved parameter set.

lst guess simulation. We assumed that all the parameters of the model are correct except $\Sigma_{1}$, $\Sigma_{2}$ and $\alpha$. The values prescribed to $\Sigma_{1}(1000$ degree.days instead of 600 for reference) and $\Sigma_{2}$ (3700 d.d instead of 3200 ) roughly correspond to a 35 days shift in the start of the growing season and the senescence period. These errors are "reasonable", because global scale phenology modelling is not yet well established. The allocation coefficient $\alpha$ was fixed to 0.45 instead of 0.48 . The LAI time profile generated with this parameter set is displayed on Fig. 1. This figure also illustrates the sensitivity of the model to the chosen parameters. GPP and NPP values drop from 1011 to $740 \mathrm{~g} \mathrm{C} \mathrm{m}^{-2}$ year $^{-1}(-26 \%)$ and from 625 to $392 \mathrm{~g} \mathrm{C} \mathrm{m}^{-2}$ year $^{-1}(-37 \%)$ respectively, mainly because photosynthesis, for first guess simulation, occurs when temperature and daily irradiance are depleted.

Assimilation of perfect "observation"-feasibility. The objective here is to verify if the information content of the "observed" reflectances allows the retrieval of the reference LAI time profile and the reference parameter set. Inversion is performed through an iterative minimization process, starting from the 1st guess parameters. The cost function, which is minimized to find the best agreement between model and observations, was computed as follows:

$$
\begin{aligned}
& J\left(\Sigma_{1}, \Sigma_{2}, \alpha\right)=\sum_{i=1 . \ldots 52}\left[\left(\rho_{1, i}^{\mathrm{mod}}-\rho_{1, i}^{\mathrm{obs}}\right)^{2}\right. \\
& \left.+\left(\rho_{2, i}^{\mathrm{mod}}-\rho_{2, i}^{\mathrm{obs}}\right)^{2}\right]
\end{aligned}
$$

where $\rho_{1, i}^{\text {mod }}$ is the visible reflectance of week $i$ computed from the vegetation model with current $\Sigma_{1}, \Sigma_{2}, \alpha, \rho_{2, i}^{\text {mod }}$ is the corresponding near infra-red reflectance; $\rho_{1, i}^{\text {obs }}$ and $\rho_{2, i}^{\text {obs }}$ are the "observed" reflectances obtained for week $i$ with the reference simulation. This cost function exhibits discontinuities and local plateaux in response to $\Sigma_{1}$ or $\Sigma_{2}$ variations. For this reason, we chose the downhill simplex method (Matlab, from The MathWorks, Inc.) to minimize it. This algorithm allows a very good retrieval of the parameters (Table 1) when clean observations are assimilated in the model. These parameters result in the same LAI profile as the reference one. Bearing in mind the strong assumption of a "perfect model", one can notice that reflectances for the periods when LAI is below 3 allow the restitution of the complete profile of LAI, when model knowledge is taken into account. In this perspective, it is particularly interesting to study the stability of the assimilation scheme.

Assimilation of noisy "observations"-stability. As a step towards real data, we investigate the stability of the assimilation scheme when a gaussian noise is added to each synthetic observation. The objective is to assess the quality of the retrieved parameters, in a statistic sense, and the consequences on carbon fluxes. The assumption of a perfect model still holds, but this simulates perturbations of the satellite measurements. We computed 50 reflectance time series by adding a gaussian noise of zero mean and standard deviation of 0.02 . This value corresponds to $16 \%$ of the mean visible reflectance and $5 \%$ of the mean near infrared reflectance. The results of the 50 retrievals are displayed in Table 2, the

Table 2. Retrieved parameters, mean and standard deviation, after assimilation of noisy observations, for 50 experiments

\begin{tabular}{lccccc}
\hline & & & $\mathrm{GPP}$ & $\mathrm{NPP}$ \\
& $\Sigma_{1}$ (d.d) & $\Sigma_{2}$ (d.d) & $\alpha$ & $\left(\mathrm{g} \mathrm{C} \mathrm{m}^{-2} \mathrm{yr}^{-1}\right)$ & $\left(\mathrm{g} \mathrm{C} \mathrm{m}^{-2} \mathrm{yr}^{-1}\right)$ \\
\hline mean & 602.6 & 3202.3 & 0.479 & 1000 & 623 \\
std dev. & 23 & 51 & 0.019 & 30 & 20 \\
\hline
\end{tabular}


parameter means and standard deviations show how errors in the observations are propagated by the assimilation scheme. The biases on parameters are less than $4 \%$ as are the biases on resulting GPP $\left(1000 \mathrm{~g} \mathrm{C} \mathrm{m}^{-2}\right.$ year $^{-1}$ instead of 1010 for reference) and NPP $\left(623 \mathrm{~g} \mathrm{C} \mathrm{m}^{-2}\right.$ year $^{-1}$ instead of 625) The standard deviations of the parameters and annual carbon fluxes are satisfactory, and the $\mathrm{CO}_{2}$ fluxes are greatly improved (in amplitude and phasing) compared to the fluxes computed with a priori parameters chosen for the first guess. These results show that the assimilation scheme is stable, and also that the simplex algorithm statistically finds the best agreement between model and "observations". It confirms also that a temporal knowledge-based link between satellite observations at different dates can yield to accurate LAI retrieval even when high LAI values and noisy measurements are considered. These different results show that control by remote sensing data seems to be possible, for this vegetation model, which is designed for global scale satellite assimilation. Moreover, assimilation can improve both amplitude and phasing of terrestrial carbon fluxes. However, two important questions were not addressed in this experiment: the ability of the model to simulate real vegetation, and the accuracy of reflectances modelling from vegetation model outputs.

\section{Real data assimilation in a crop growth model}

This section presents a real example of the assimilation of satellite observations in a vegetation functional model. The temperate agricultural regions have been chosen as a preferred field of investigation for the following reasons: (1) Accurate production models exist for the major crops. The mechanistic or empirical relations which describe the various biophysical processes have been established in ecophysiology and agronomy for several decades. Resulting models are able to simulate the growth and the development of a crop canopy at a daily time step in order to estimate accurately grain production (yield) as a function of the driving meteorological data, mainly solar radiation, temperature and precipitation, as well as soil and farming practices. A number of parameters used in this kind of models have a clear biological or physical meaning with a rather well known range of values, and the complete set of mechanistic or empirical relations prevent the model from diverging drastically. (2) We can find major crop areas where many environmental factors are controlled: nutrients are generally sufficient (fertilizers), pests are controlled, and irrigation techniques can provide the adequate water. Consequently, vegetation behavior is mostly dependant on the solar radiation and temperature encountered at the various phenological stages, which means that the timing of the phenology during the seasonal cycle is the fundamental point. (3) Some information about farming practices and yields are available from agricultural services at a scale compatible with remote sensing observations. (4) Most of the ground radiometric experiments over vegetation have concerned crop canopies, where the SAIL model has been validated. We are then in its precise applicability conditions. (5) The radiative signal over crop fields during the annual cycle shifts from the reflectance of a bare soil to the reflectance of a dense and very active canopy. Its amplitude is more important than that of most natural ecosystems, and leads to an easier use of the satellite signal.

The region of interest here is the Beauce region $\left(7500 \mathrm{~km}^{2}\right)$, South-West of Paris, France. Winter cereals (wheat and barley) cover more than $60 \%$ of the surface and generally reach very good yields due to the pedoclimatological conditions. For wheat, we use the ARCWHEAT2 production model (Porter, 1993): the driving meteorological variables are the daily values of: minimum and maximum temperature, global incident solar radiation, water vapor pressure, precipitation. Photosynthesis is computed at a hourly time step, and respiration at a daily one. Following that, $\mathrm{CO}_{2}$ exchanges are simulated to determine dry matter accumulation. The development of the canopy, which is constrained by the amount of photosynthetic assimilates sent to the leaves, is essentially driven by temperature and daylength. For. each variety, the parameters are, for instance, the amount of cumulated temperatures required between the various phenological stages. The accuracy of the description of the cover development is a fundamental point because the LAI temporal profile directly drives the amount of sun radiation absorbed by the canopy and used for the photosynthesis. A good description of the 
phenology is then essential. With the meteorological conditions of a particular year, the sowing date is the most evident pertinent parameter for the phenology (which is also sensitive to a few parameters related to the photoperiod and depending on the variety). Following that, among the various parameters which are generally not well known at the regional level, and which have a strong influence on the estimated NPP, a sensitivity study has shown than the sowing date is the most important. We discuss hereafter the use of satellite data in order to estimate the sowing date.

\subsection{Coupling ARCWHEAT2 and SAIL models at the field scale and comparison with observa- tions}

Data. The satellite observations used here are high resolution data, in order to distinguish the individual fields. Over the Beauce region, 4 SPOT images were available during the wheat growing season in 1992. The dates and angles of acquisition are shown in Table 3. The first image corresponds to the beginning of the spring growth, in April, after the winter dormancy, and the three other images were acquired at the maximum of activity and development of the wheat canopy, in May. Data processing provides surface reflectances values in the red and near infrared channels at the canopy level.

Model. To simulate the annual profile of the visible and near infrared reflectances over the canopy, SAIL uses the daily LAI computed by

Table 3. SPOT acquisitions over the Beauce region during the wheat growing season

\begin{tabular}{rcccrc}
\hline Dates (day of year) & Hour & $\theta_{\mathrm{s}}$ & $\varphi_{\mathrm{s}}$ & $\theta_{\mathrm{v}}$ & $\varphi_{\mathrm{v}}$ \\
\hline 9 April 1992(100) & $11 \mathrm{~h} 09$ & 42.1 & 162.6 & 6.6 & 104 \\
13 May 1992(134) & $11 \mathrm{~h} 14$ & 30.9 & 163.0 & 16.8 & 105 \\
18 May 1992(139) & $11 \mathrm{~h} 18$ & 29.6 & 164.7 & 22.7 & 106 \\
19 May 1992(140) & $10 \mathrm{~h} 58$ & 30.5 & 155.4 & 4.3 & 282 \\
\hline
\end{tabular}

For each date, the day of year is given in parenthesis. $\theta_{\mathrm{s}}$ and $\varphi_{\mathrm{s}}$ are the solar zenith and azimuth angles, $\theta_{\mathrm{v}}$ and $\varphi_{\mathrm{v}}$ are the viewing zenith and azimuth angles, in degrees. These angles are taken into account in the SAIL radiative transfer model to compute the bidirectional reflectances over the canopy in the same configuration as they are observed by SPOT.
AFRCWHEAT2, the position of the sun, and the position of the sensor, assumed to be at nadir, as daily input variables. The optical properties of leaves and soil, and the distribution of the inclination of the leaves (spherical) are input parameters. Their values and the reasons for such a choice are described in Moulin and Fischer (1993). For the 4 days corresponding to the SPOT data, the reflectances are also computed by using the real acquisition angles, as they are indicated in Table 3.

Comparison. To validate the linking of these two models, we choose some specific fields where useful information, for instance the sowing date and the variety, are available. We can then run the model with the appropriate values for these parameters. An estimated value of the yield is given by the farmer, allowing a qualitative comparison with the grain production simulated by the model. An example of the result of the coupling of the two models is shown in Fig. 4. We must be careful with our conclusions because the number of observations is limited, however, we can observe a good agreement between model and data for the visible reflectance, and also for the near infrared reflec-

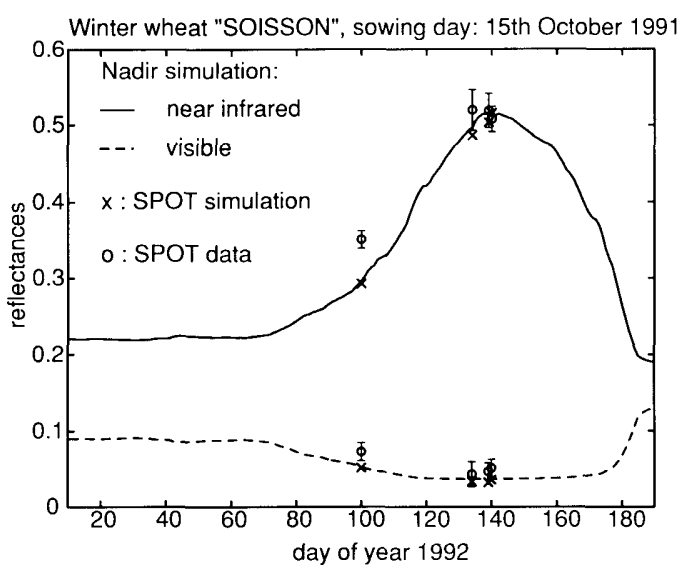

Fig. 4. Seasonal profile of the near infrared and visible reflectances over a winter wheat canopy simulated by the coupling of the crop production model AFRCWHEAT2 and the radiative transfer model SAIL. Comparison with the measured reflectances at 4 dates of SPOT observations. The reflectances are simulated at nadir all along the year. For the 4 dates of SPOT acquisitions, another computation is done by taking into account the view angles in order to simulate the reflectances in the conditions of observation. 
tance in May, day of year (doy) 130 to 140 , when the canopy is well developed and very active. The main explanation of the under estimation of the simulated near infrared reflectance in April (doy $100)$, compared to the observations is that the SAIL model is applied with the assumption of a closed canopy. At the beginning of April, the canopy is sparse, and the computation of reflectance at the canopy level should take into account the contribution of the soil reflectance and of the reflectance of the green components. Preliminary tests have shown that the simulated near infrared reflectance is closer to the observations when the fractional cover is taken into account. Consequently, it seems possible to improve the linking of a crop model and a radiative transfer model. Besides, the grain production simulated by the model is $8900 \mathrm{~kg} / \mathrm{ha}$ when the estimated yield given by the farmer is $9000 \mathrm{~kg} / \mathrm{ha}$. Then, the two following considerations: (a) the simulated reflectances are in good agreement with the observed reflectances, and (b) the simulated production is coherent with the farming information, suggest that we may be confident in the various processes described by the model: $\mathrm{CO}_{2}$ fluxes, $\mathrm{H}_{2} \mathrm{O}$ fluxes, NPP, biomass of the various elements.

\subsection{Assimilation of the observations}

Section 4.1 showed that it is possible to describe the reflectance time profiles by the mean of a functional model able to simulate interesting outputs regarding the productivity. Our interest is the possibility of using the satellite observations with the same strategy as previously defined. The assimilation of the satellite data should lead to the adjustment of poorly known parameters in order to obtain the best coherence between the model and the data. Because we have 4 observations during the wheat growing season, we are going to focus on only one parameter. For estimation of NPP at a regional level, a very important initial condition for the model is the sowing day. As stated before, this parameter strongly drives the phenology, the seasonal profiles of the reflectances and of the $\mathrm{CO}_{2}$ exchanges. Consequently, it has a fundamental effect on the NPP estimation. The effect of the change of the sowing date on the modelled near infrared reflectance profile is essentially a shift of the ascending branch. Although the number of available observations is reduced, we expect that these 4 images will allow us to control the timing of the development of the canopy, by adjustment of the "best" value for the sowing day.

The experiment will consist of trying to retrieve the most probable value of the sowing date for the Beauce region. We focus on a $40 \times 40 \mathrm{~km}$ square. The agroclimatological conditions on this site are considered homogeneous, which means that all the fields covered by a particular crop show a rather similar canopy behavior. For each SPOT acquisition, we compute the average near infrared reflectance of the fields classified as wheat. We have then four data that we call "regional observations" for the wheat canopy. According to the agricultural statistics of the region, the most frequent sowing day in 1991 was the 15th of October (doy 288). We can verify that the run of the model with such an initial condition agrees with the regional observations (full curve of the Fig. 5). In the following part, that profile is called "reference profile".

In our test, the model is run with an initial value for the sowing date (1st guess). The same optimization algorithm as in 2.2 (simplex) is used to determine the value of the sowing date which leads to the minimum of differences between the simulation and the observations. 7 initial values for the sowing date have been tested, in a range of plus or minus one month around the 15 th of

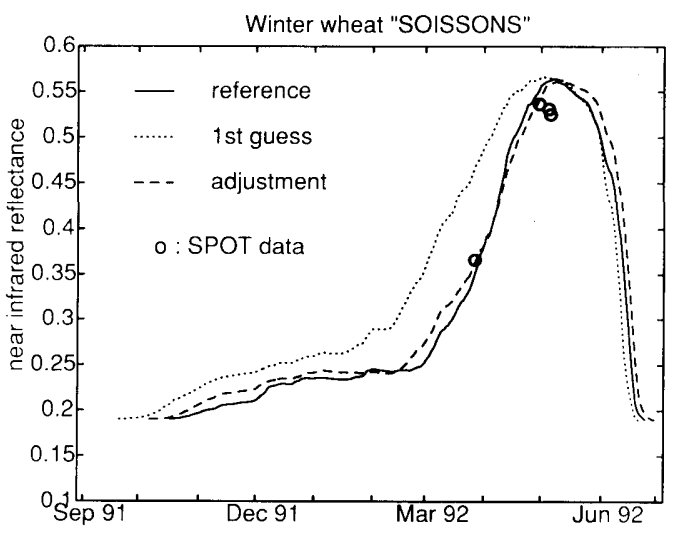

Fig. 5. Change in the near infrared profile due to the adjustment of the sowing date. The SPOT data are the average near infrared reflectances over all the wheat fields of the studied site. The adjusted profile is very close to the reference profile, plotted with the value of the sowing date which is the most represented according to the agricultural services. 
October. An example is plotted on Fig. 5: the initial sowing day is the 25th of September (doy 268 ), and the retrieved sowing day after adjustment is the 14th of October (doy 287). We have observed some sensitivity to the choice of the initial value. For 5 cases, the result is excellent: the 15th of October date, which is known to be the most frequent sowing day, is retrieved with a maximum variation of 1 day. In 2 special cases, the minimization procedure does not find the absolute minimum of the cost function. The iterations stop at a local minimum, which corresponds to a date 8 or 9 days too early. These 2 cases are not obtained for the initial values the farthest from the "reference" one, and there is no simple interpretation of such a result. Because we try to adjust only one parameter, it could have been simpler to systematically compute the cost function on the whole set of possible values for the sowing day. Moreover, this parameter only takes integer values, which considerably reduces the number of runs. In that case, the absolute minimum is always found. However, it is interesting to look at the results of a more general minimization algorithm, usable in any case: with several parameters which can vary in a continuous way (this also maintains coherence with Section 2). Without further investigations on the various mathematical methods here, we simply conclude that the minimization procedure "downhill simplex method", must be used with care. The first minimum found by the algorithm may not be the right one, so two or three runs with different first guesses must be tried if we decide to use this minimization procedure.

A particular interest of the adjustment of the sowing date is the possibility to improve the NPP estimation. The histogram of the seasonal NPP estimated from different initial values of the sowing day is shown in Fig. 6. We can see the changes between the NPP result with the sowing date used in the first guess and the NPP result with the adjusted sowing date. The NPP value estimated by the model in the case of what we call the "reference" profile $\left(2790 \mathrm{~g} \mathrm{C} \mathrm{m}^{-2}\right.$ year $^{-1}$, for a sowing on the 15th of October, doy 288) is indicated by the dashed line. We have computed the changes in the relative error of the estimated NPP after the adjustment. The average relative error which is $7.2 \%$ before adjustment decreases to $3.2 \%$ when the satellite observations are used. The two particular cases, when the iterations do not

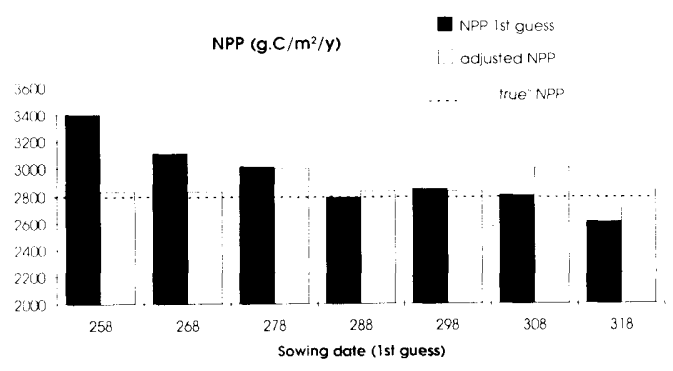

Fig. 6. Changes in the estimated NPP due to the adjustment of the sowing date depending on the initial value chosen for the lst guess. Comparison with the estimated NPP value which corresponds to the reference profile.

find the "correct" sowing date, prevent this result from being better.

This section has tested the assimilation of satellite observations in a crop model. This demonstrates that vegetation models, for crops at least, describe the canopy development with sufficient accuracy to be coupled with satellite data and that reflectance model leads to satisfying results. We conclude that we are confident in the combined use of satellite data and functional models with such an approach improving the various biological outputs of the model, but that the minimization algorithm must be carefully applied.

\section{Discussion}

Our theoretical considerations, the results of the synthetic study and application to real vegetation and measurements suggest that controlling a prognostic vegetation model by satellite data can improve the accuracy of the model outputs. This is a new approach in the field of vegetation functioning studies, and some remarks can be made to point out particular questions. The method that we propose is a "model to satellite" approach (Hollingsworth, 1990), insofar as it uses direct modelling from the vegetation model to the remote sensor. One can try to retrieve, as a first step, some biophysical variable (e.g., weekly LAI or APAR), and to find agreement between the evolution in the vegetation model and the retrieved data (a step towards "satellite to model" approach). In theory, the first method should lead to better results, avoiding errors in LAI inversion. This inversion 
requires a strong filtering of the radiometric measurements which are based on a priori knowledge (for example maximum value composite of NDVI, Holben, 1986). In particular, recent methods (BISE: Viovy et al., 1992) assume a minimum time for canopy decrease and regrowth. Clearly, this a priori knowledge is included in the "model to satellite" approach. However, it requires accurate direct modelling of reflectances, and therefore LAI and optical properties temporal profiles. Developments of LAI measurements (with portable optical sensors) are expected to result in better understanding and modelling of canopy behavior for natural ecosystems. Modelling the structure of vegetation canopies and their seasonal variations is a critical issue (a) for carbon cycle assessment, (b) for coupling with satellite data but also (c) for climate research (Pielke et al., 1993). In this study, we focused on seasonal vegetation and satellite measurements in the solar spectrum. Therefore, for global scale applications, savannahs, steppes and deciduous forests ecosystems are natural candidates for vegetation model control by satellite observations. Moreover, the first information which is expected concerns phenology modelling. Besides, inclusion of measurements from other sensors or wavelengths is straightforward, for example by adding properly weighted terms in the cost function, when accurate direct modelling from vegetation to satellite exists. Water in plant and soil, latent heat fluxes, canopy biomass, structure and temperature have been related to microwave and thermal infrared measurements (Kerr and Njoku, 1993). Finally, we outline how the development of vegetation models and assimilation of satellite data should proceed in close connection, because the control strategy requires accurate analysis of the model errors, to determine the control variables for instance.

\section{Conclusion}

We present, in this paper, a methodology for coupling prognostic model of vegetation and remote sensing measurements. This approach postulates that errors on model parameters or initial state can be corrected, by finding the best agreement between satellite observations and reflectances. These reflectances are computed from the model state variables, (LAI for example) with a direct "scene" model. We briefly discussed the difference between this approach and previous studies dealing with the coupling of satellite data and vegetation modelling. A synthetic experiment with a generic vegetation model, designed for carbon cycle investigations, shows that processes like allocation of carbon to the leaves and phenological behavior of a deciduous-forest canopy can be controlled, and that carbon exchanges estimation is then improved. Assimilation of real satellite observations in a crop model leads to enhanced simulation of vegetation functioning, as groundtruth information confirms that a good retrieval of the sowing date is achieved. At the global scale, assimilation of coarse resolution remote sensing measurements in process vegetation models should improve seasonal and inter annual variations in NPP and $\mathrm{CO}_{2}$ fluxes estimations, especially for ecosystems with marked seasonality.

\section{Acknowledgements}

This work was carried out at the Laboratoire d'Etudes et de Recherches en Télédétection Spatiale (LERTS) as part of the European project "The global Carbon Cycle and its perturbation by man and climate. Part II: Biosphere", supported by the Environment program of the Commission of the European Communities, and as part of the project: "Synergie entre modeles de fonctionnement de la végétation et observation satellitaire", supported by the Région Midi-Pyrénées under grant $n^{\circ} 9200795$. Laurent Kergoat is supported by CNRS-INSU, and Sophie Moulin by the French Ministry of Research and Technology. The authors gratefully thank John R. Porter for providing the code of the ARCWHEAT2 model. The MARS project (JRC, Ispra) is acknowledged for providing the SPOT data, and SOTEMA for processing them.

\section{Appendix}

This section details eq. (2.1).

Allocation and phenology have been discussed in Section 3. 
Photosynthesis:

$\mathrm{Pn}=\mathrm{D}_{\text {aylength. }} \int_{l=0}^{\mathrm{LAI}} \frac{\Delta \mathrm{CO}_{2}}{R_{\text {stom }}+R_{\text {meso }}(l)} \mathrm{d} l$.

Stomatal and mesophyll resistance models are taken from Running and Coughlan (1988) (dependence on air temperature and humidity, soil water content) the photosynthetic rate is integrated over the canopy, assuming an exponential extinction of light with depth.

Autotrophic respiration is the sum of maintenance and growth respiration: $\mathrm{Ra}=\mathrm{Rm}+\mathrm{Rg}=$ $a \mathrm{e}^{b T} M_{i}+c \Delta M_{i}$, where $M_{i}$ is the carbon content of the compartment, $\Delta M_{i}$ the daily allocation of carbon to $M_{i}$.

Senescence and translocation from storage are constant fluxes for each phenological stage.

Transpiration rate $\mathrm{Tr}$ is computed according to the Penman-Monteith formula.

Water bucket model:

$\frac{\mathrm{d} W}{\mathrm{~d} t}=\operatorname{Pr}-\operatorname{Tr}-R$

where $W$ is the soil water content, $\operatorname{Pr}$ daily precipitation, $R$ runoff or drainage, which occurs when $W>W_{\max }$; parameter set:

\begin{tabular}{|c|c|c|c|}
\hline & $\begin{array}{c}\text { Carbon } \\
\text { initial } \\
\text { value }\end{array}$ & Maintenance & $\begin{array}{l}\text { Growth } \\
\text { resp. }\end{array}$ \\
\hline leaves & 0.0 & 0.00015 & 0.10 \\
\hline stem & 5.0 & 0.00004 & 0.10 \\
\hline fine roots & 0.0 & 0.0002 & 0.10 \\
\hline storage & 0.38 & 0.0 & 0.10 \\
\hline units & $\mathrm{kg} \mathrm{C} \mathrm{m}^{-2}$ & $\mathrm{~kg} \mathrm{C} \mathrm{kg} \mathrm{C}^{-1} \mathrm{day}^{-1}$ & $\mathrm{~kg} \mathrm{C} \mathrm{kg} \mathrm{C}^{-1}$ \\
\hline
\end{tabular}

parameters for flux modelling are taken from Running and Coughlan (1988) except the following:

maximum mesophyll conductance:

$0.001 \mathrm{~m} \mathrm{~s}^{-1}$

maximum stomatal $\mathrm{H}_{2} \mathrm{O}$ conductance:

$0.002 \mathrm{~m} \mathrm{~s}^{-1}$;

cuticular conductance:

$0.000066 \mathrm{~m} \mathrm{~s}^{-1}$;

SLA: $15.0 \mathrm{~m}^{2} \mathrm{~kg} \mathrm{C}^{-1}$.

mortality of leaves:

$0.0008 \mathrm{~kg} \mathrm{C} \mathrm{m}^{-2}$ day $^{-1}$ during growth;

0.007 during senescence period;

translocation from storage:

$0.009 \mathrm{~kg} \mathrm{C} \mathrm{m}^{-2} \mathrm{day}^{-1}$, until storage is empty.

\section{REFERENCES}

Agren, G. I., McMurtrie, R. E., Parton, W. J., Pastor, J. and Shugart, H. H. 1991. State-of-the-art of models of production-decomposition linkages in conifer and grassland ecosystems. Ecological Applications 1, 118-138.

Bonan, G. B. 1991a. Atmosphere-biosphere exchange of carbon dioxide in boreal forests. J. Geophys. Res. 96, 7301-7312.

Bonan, G. B. 1991b. Seasonal and annual carbon fluxes in a boreal forest landscape. J. Geophys. Res. 96, 17329-17338.

Bonan, G. B. 1993. Importance of leaf area index and forest type when estimating photosynthesis in boreal forests. Remote Sens. Environ. 43, 303-314.

Farquhar, G. D., Lloyd, J., Taylor, J. A., Flanagan, L. B., Syvertsen, J. P., Hubick, K. T., Chin Wong, S. and Ehleringer, J. R. 1993. Vegetation effects on the isotope composition of oxygen in atmospheric $\mathrm{CO}_{2}$. Nature $363,439-443$.

Fung, I. Y., Tucker, C. J. and Prentice, K. C. 1987. Application of advanced very high resolution radiometer vegetation index to study atmosphere- biosphere exchange of $\mathrm{CO}_{2}$. J. Geophys. Res. 92 , 2999-3015.

Heimann, M. and Keeling, C. D. 1989. A three-dimensional model of atmospheric $\mathrm{CO}_{2}$ transport based on observed winds: (2). Model description and simulated tracer results. Geophysical Monographs 55 (American Geophysical Union), pp. 237-275.

Holben, B. N. 1986. Characteristics of maximum-value composite images from temporal AVHRR data. Int. J. Remote Sensing 7, 1417-1434.

Hollingsworth, A. 1990. Assimilation of remotely sensed atmospheric data from new satellite systems in the 1990's. Proc. of the International Symposium on Assimilation of observations in meteorology and oceanography, held in Clermont-Ferrant, France, 9-13 July 1990, WMO, I, 19-26.

Janececk, A., Benderoth, G., Lüdecke, M. K. B., Kindermann, J. and Kohlmaier, G. H. 1989. Model of the seasonal and perennial carbon dynamics in deciduous type forests controlled by climatic variables. Ecol. Mod. 49, 101-124.

Kerr, Y. H. and Njoku, E. G. 1993. On the use of passive 
microwaves at $37 \mathrm{Ghz}$ in remote sensing of vegetation. Int. J. Remote Sensing 14, 1931-1943.

Körner, Ch. 1993. Leaf diffusive conductances in the major vegetation types of the globe. In: Schulze, E. D., Goldwell, M. M. (eds.): Ecological Studies, Vol. 100. New York, Heidelberg, Berlin: Springer.

Le Dimet F. X. and Talagrand O. 1986. Variational algorithms for analysis and assimilation of meteorological observations: theoretical aspects. Tellus 38A, 97-110.

Lieth, H. 1975. Modeling the primary productivity of the globe. In: Primary productivity of the biosphere (ed. H. Lieth and R. H. Wittaker). New York. SpringerVerlag, 237-263.

Lüdeke, M., Janececk, A. and Kohlmaier, G. K. 1991. Modelling the seasonal $\mathrm{CO}_{2}$ uptake by land vegetation using the global vegetation index. Tellus 43B, 188-196.

Mellilo, J. M., McGuire, A. D., Kicklighter, D. W., Moore, B., Vorosmarty, C. J. and Schloss, A. L. 1993. Global climate change and terrestrial net primary production. Nature 363, 234-240.

Monteith, J. L. 1972. Solar radiation and productivity in tropical ecosystems. Journal of Applied Ecology 9, 744-766.

Moulin, S. and Fischer, A. 1993. Simulation of the temporal variations of NOAA/AVHRR reflectances. Coupling of functional model and satellite data. Proc. of the 6th AVHRR Data Users' Meeting, held in Belgirate (Italy), 26 June-1 July 1993, pp. 277-283.

Murray, M. B., Cannell, M. G. R. and Smith, R. I. 1989. Date of budburst of fifteen tree species in Britain following climatic warming. Journal of Applied Ecology 26, 693-700.

Nemani, R. R. and Running, S. W. 1989. Testing a theoretical climate-soil-leaf area hydrologic equilibrium of forest using satellite data and ecosystem simulation. Agric. For. Meteorol. 44, 245-259.

Nisinski, J. J. and Saugier, B. 1988. A model of leaf bud- ding and development for a mature Quercus forest. $J$. Appl. Ecology 25, 643-652.

Pielke, R. A., Schimel, D. S., Lee, T. J., Kittel, T. G. F. and Zeng, X. 1993. Atmosphere-terrestrial ecosystem interactions: implications for coupled modeling. Ecol. Modell. 76, 15-18.

Porter, J. R. 1993. AFRCWHEAT2: A model of the growth and development in wheat incorporating responses to water and nitrogen. Eur. J. Agron. 2, 69-82.

Ruimy, A., Saugier, B. and Dedieu, G. 1994. Methodology for the estimation of terrestrial net primary production from remotely sensed data. Journal of Geophysical Research 99 D3, 5263-5283.

Running, S. W., Nemani, R. R., Peterson, L. D., Band, L. E., Potts, D. F., Pierce, L. L. and Spanner, M. A. 1989. Mapping regional forest evapotranspiration and photosynthesis by coupling satellite data with ecosystem simulation. Ecology 70, 1090-1101.

Running, S. W. and Coughlan, J. C. 1988. A general model of forest ecosystem processes for regional applications (I). Hydrological balance, canopy gas exchange and primary production processes. Ecol. Model. 42, 125-154.

Sarmiento, J. L. 1993. Atmospheric $\mathrm{CO}_{2}$ stalled. Nature 365, 697-698.

Verhoef, W. 1984. Light scattering by leaf layers with application to canopy reflectance modeling: the SAIL model. Remote Sens. Environ. 16, 125-141.

Viovy, N., Arino, O. and Belward, A. S. 1992. The best index slope extraction (BISE): A method for reducing noise in the NDVI time-series. Int. J. Remote Sensing 13, 1585-1590.

Woodward, F. I. and Smith, T. M. 1994. Global photosynthesis and stomatal conductance: modelling the controls by soil and climate. Advance in Botanical Research 20, 1-41. 